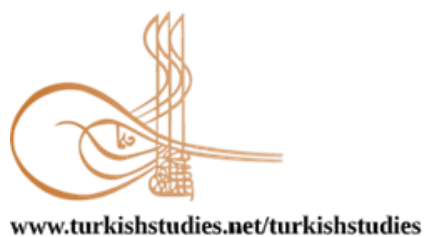

Turkish Studies

\title{
“Covid-19 Hijyen Ölçeği”: Bir Ölçek Geliştirme Çalışması
}

\author{
"Covid-19 Hygiene Scale": A Scale Development Study
}

\author{
Birgül Ç̧çek $^{*}$ - Hande Şahin ${ }^{* *}$ - Sibel Erkal ${ }^{* * *}$
}

\begin{abstract}
This study, which was planned to develop a scale in order to determine the hygiene-oriented behaviors of individuals during the Covid-19 pandemic, was carried out with 837 individuals by the simple random sampling method through an online questionnaire for adults with different socioeconomic characteristics. Before starting the study, the approval of the ethics committee numbered 35853172-200 was obtained at the meeting of Hacettepe University Ethcis Committee on July 28, 2020. After the data of the study were collected, the descriptive information was tabulated as number and percentage, and Confirmatory Factor Analysis (CFA) was performed to test the construct validity of the scale. SPSS v.23.0 and SPSS AMOS Graphics v23.0 programs were used for statistical analysis. Cronbach's alpha coefficient of the 27 -item scale was evaluated at a $95 \%$ confidence interval and was found to be 0.908 . Accordingly, the Covid-19 Hygiene Scale was found to be "highly reliable". In this study, in order to determine the hygiene behavior of individuals during the Covid-19 pandemic, the "Covid-19 Hygiene Scale" consisting of 27 items and 6 sub-dimensions, including "Changing Hygiene Behaviors in the Pandemic", "Home Hygiene", "Social Distance and Wear of Masks", "Shopping Hygiene", "Hand Hygiene" and "Hygiene When Coming Home from Outside" was developed. All items are rated on a 5-point scale from "never (1)" to "always (5)." In the present study total scale scores ranged from 27 to 135 . Considering the construct and content validity of this scale, which was prepared to determine the behaviors of individuals towards personal and general hygiene during the Covid-19 pandemic, it is thought that the scale can be used in studies on the subject.
\end{abstract}

Structured Abstract: This study, which was planned to develop a scale in order to determine the hygieneoriented behaviors of individuals during the Covid-19 pandemic, was carried out with 837 individuals by the simple random sampling method through an online questionnaire for adults with different socioeconomic characteristics.

\footnotetext{
* Arş. Gör., Hacettepe Üniversitesi, İ̈BF Aile ve Tüketici Bilimleri Bölümü Res. Assist., Hacettepe University, Faculty of Economics and Administrative Sciences, Family and Consumer Sciences ORCID 0000-0002-3985-6637

birgulaydin@hacettepe.edu.tr

***Prof. Dr., Kırıkkale Üniversitesi, Sağlık Bilimleri Fakültesi, Sosyal Hizmet Bölümü

Prof. Dr., Kirlkkale University, Faculty of Health Sciences, Department of Social Services

ORCID 0000-0002-0012-0294

hande_k1979@yahoo.com

**** Prof. Dr., Hacettepe Üniversitesi, İİBF Aile ve Tüketici Bilimleri Bölümü

Prof. Dr., Hacettepe University, Faculty of Economics and Administrative Sciences, Family and Consumer Sciences

ORCID 0000-0002-8395-9705

serkal@ hacettepe.edu.tr

Cite as/ Atıf: Çiçek, B., Şahin, H. \& Erkal, S. (2020). "Covid-19 Hijyen Ölçeği”: Bir ölçek geliştirme çalışması. Turkish

Studies, 15(6), 339-350. https://dx.doi.org/10.7827/TurkishStudies.45906

Received/Geliş: 23 August/Ağustos 2020

Checked by plagiarism software

Accepted/Kabul: 15 October/Ekim 2020

Published/Yayın: 20 October/Ekim 2020

Copyright $(\mathcal{C}$ MDE, Turkey

CC BY-NC 4.0
} 
After the data of the study were collected, the descriptive information was tabulated as number and percentage, and Confirmatory Factor Analysis (CFA) was performed to test the construct validity of the scale. SPSS v.23.0 and SPSS AMOS Graphics v23.0 programs were used for statistical analysis.

Of the individuals participating in the study, $74.6 \%$ are female, and $25.4 \%$ are male. Of the participants, $73.4 \%$ are married, and $36.9 \%$ are aged between $35-49$ years. Of the participants, $63.3 \%$ stated that they have an income of $6000 \mathrm{TL}$ and above in terms of the total monthly income of the family, and almost half of the participants (52.3\%) have a bachelor's degree. When the employment status of the individuals participating in the study in accordance with the measures taken during the pandemic period was examined, it was determined that $24.9 \%$ of the participants work from home and $17.6 \%$ go to work on some days. Furthermore, $52.6 \%$ of the participants $(n=252)$, who stated that they work during the pandemic period apart from those working from home, stated that they have physical interaction with other people due to their job.

Cronbach's alpha coefficient of the 27 -item scale was evaluated at a $95 \%$ confidence interval and was found to be 0.908 . Alpar (2011, p.815) explains the internal reliability coefficient between .80 and 1.00 as "highly reliable," and between .60 and .79 as "very reliable." Accordingly, the Covid-19 Hygiene Scale was found to be "highly reliable," and all sub-dimensions of the scale were found to be "very reliable."

According to the findings obtained as a result of the Confirmatory Factor Analysis, the values of $\chi 2 / \mathrm{df}$ $=4.509, p<.001, \mathrm{GFI}=.885, \mathrm{AGFI}=.859$, and $\mathrm{RMSEA}=.065$ were obtained. While the $\chi 2 / \mathrm{df}$ ratio below 2 indicates a good fit, the ratio below 5 indicates an acceptable fit (Jabeen \& Hamid, 2019; Kline, 2010; Şimşek, 2007). The RMSEA value lower than or equal to .05 indicates a good fit, the RMSEA value between .05 and .08 indicates a sufficient fit, and the RMSEA value between .08 and .10 indicates a weak fit. The AGFI and GFI values show a perfect fit over .95 and a good fit at .90 and above (Hu \& Bentler, 1999; Schumacker \& Lomax, 1996). When the values are examined, although $\mathrm{GFI}=.885<.90$ and $\mathrm{AGFI}=.859<.90$ showing the model fit were slightly below the expected values, it was concluded that the scale model had a sufficient fit.

In this study, in order to determine the hygiene behavior of individuals during the Covid-19 pandemic, the "Covid-19 Hygiene Scale" consisting of 27 items and 6 sub-dimensions, including "Changing Hygiene Behaviors in the Pandemic", "Home Hygiene", "Social Distance and Wear of Masks", "Shopping Hygiene", "Hand Hygiene" and "Hygiene When Coming Home from Outside" was developed.

The lowest score that can be obtained from the scale is 27 , and the highest score is 135 . The high score obtained indicates that individuals have a high level of behavior related to personal and general hygiene in order to protect themselves against the pandemic, and they attach importance to hygiene measures.

The "Changing Hygiene Behaviors in the Pandemic" sub-dimension consists of 6 items (C. alpha: .749) that include some hygiene behaviors that individuals exhibit more than before the pandemic. The lowest score that can be obtained from this sub-dimension is 6 , and the highest score is 30 . The high score obtained indicates that individuals adopt new hygiene-related behaviors in order to protect themselves against the pandemic and exhibit their current behaviors more frequently.

The "Home Hygiene" sub-dimension includes 4 items (C. alpha: .690) related to the general hygiene of the home in order to protect themselves against the pandemic. The lowest score that can be obtained from this sub-dimension is 4 , and the highest score is 20 . The high score obtained from this sub-dimension indicates that individuals have a high level of behavior related to home hygiene in order to protect themselves against the pandemic and they attach more importance to home hygiene.

The "Social Distance and Use of Masks" sub-dimension consists of 4 items (C. alpha: .688) related to the protection of social distance with other people and the use of masks in order to protect themselves against the pandemic. The lowest score that can be obtained from this sub-dimension is 4 , and the highest score is 20 . The high score obtained indicates that individuals attach importance to the social distance and use of masks in order to protect themselves against the pandemic and make efforts for this.

In the "Shopping Hygiene" sub-dimension, there are 5 items (C. alpha: .742) related to the measures taken by individuals to minimize the effects of coronavirus during and after shopping. The lowest score that can be obtained from the sub-dimension is 5, and the highest score is 25 . The high score obtained indicates that individuals take hygiene measures during and after shopping to minimize coronavirus transmission routes. 
The "Hand Hygiene" sub-dimension consists of 5 items (C. alpha: .702) related to hand cleaning and hygiene, which are the most effective way of protection from coronavirus. The lowest score that can be obtained from the sub-dimension is 5 , and the highest score is 25 . The high score obtained indicates that individuals have a high level of behavior related to hand hygiene in order to protect themselves against the pandemic and they pay significant attention to hand hygiene.

Another sub-dimension is "Hygiene When Coming Home from Outside." There are 3 items (C. alpha: .698) related to the measures taken by individuals who go out for working, shopping, or other purposes and enter crowded environments in order to protect themselves from coronavirus when they come home. The lowest score that can be obtained from the sub-dimension is 3, and the highest score is 15 . The high score obtained indicates that individuals apply a high level of hygiene rules after coming home from outside in order to protect themselves against the pandemic.

Considering the construct and content validity of this scale, which was prepared to determine the behaviors of individuals towards personal and general hygiene during the Covid-19 pandemic, it is thought that the scale can be used in studies on the subject.

Keywords: Covid-19 hygiene scale, Covid-19, hygiene, scale

Öz: $\mathrm{Bu}$ çalışma, Covid-19 salgını sürecinde bireylerin hijyen davranışlarını belirlemek için bir ölçek geliştirilmesi amacıyla planlanmış, farklı sosyoekonomik özelliklere sahip basit rastgele örnekleme yöntemi ile ulaşılan 837 yetişkin birey çevrimiçi anket yoluyla çalışmaya katılmıştır. Araştırmaya başlamadan önce Hacettepe Üniversitesi Etik Komisyonunun 28 Temmuz 2020 tarihli toplantısında 35853172-200 sayılı etik kurul onayı alınmıştır. Veriler toplandıktan sonra tanımlayıcı bilgiler sayı ve yüzde şeklinde tablolaştırılmış, ölçeğin yapı geçerliliğinin test edilebilmesi için Doğrulayıcı Faktör Analizi (DFA) yapılmıştır. İstatistiksel analizler için SPSS v.23.0 ve SPSS AMOS Graphics v23.0 programları kullanılmıştır. Ölçeğin güvenirliği için Cronbach Alpha iç tutarlılık katsayına bakılmış, \%95 güven aralığında değerlendirilmiş ve 908 olarak bulunmuştur. Buna göre; Covid-19 Hijyen Ölçeği “yüksek derecede güvenilir” olduğu belirlenmiştir. Sonuç olarak Covid-19 salgın döneminde bireylerin kişisel ve genel hijyene yönelik davranışlarını belirlemek amacıyla "Salgınla Değişen Hijyen Davranışları", "Ev Hijyeni”, "Sosyal Mesafe ve Maske Kullanımı", Alışveriş Hijyeni", "El Hijyeni" ve "Dışarıdan Eve Gelindiğinde Hijyen” olmak üzere 6 alt boyuttan oluşan 27 maddelik “Covid-19 Hijyen Ölçeği” geliştirilmiştir. Ölçekte 5'li derecelendirme (5 puan 'Her zaman', 1 puan 'Hiçbir zaman') kullanılmıştır. Ölçekten alınabilecek en düşük puan 27, en yüksek puan ise 135'tir. “Covid-19 Hijyen Ölçeği’nin yapı ve kapsam geçerliliğinden elde edilen sonuçlar; ölçeğin konuyla ilgili çalışmalarda geçerli ve güvenilir bir ölçme aracı olarak kullanılabileceğini göstermektedir.

Anahtar Kelimeler: Covid-19 hijyen ölçeği, Covid-19, hijyen, ölçek

\section{Giriş}

İlk olarak Çin'in Wuhan eyaletinde ortaya çıkan ve Ocak 2020 itibariyle tanımlanan Yeni Tip Koronavirüs (Covid-19) salgını üç ay gibi kısa bir süre içerisinde tüm dünyayı etkisi altına almıştır. Dünyada hızla yayılmasıyla birlikte Dünya Sağlık Örgütü (WHO) 11 Mart 2020'de Yeni Tip Koronavirüsü (Covid-19) küresel salgın anlamına gelen pandemi olarak ilan etmiştir (WHO, 2020). Aynı zamanda bu tarihte Türkiye'de ilk olarak Covid-19 vakası görülmüştür (T.C. Sağlik Bakanlığ 1 , 2020). Koronavirüsün, insandan insana; konuşma, hapşırma ya da öksürmeyle birlikte dışarı çıkan küçük damlacıklar yoluyla bulaştığı bilinmektedir. Semptom gösteren veya göstermeyen hasta bireylerden dağılan bu damlacıkların bulunduğu yüzeye temas eden sağlıklı bireylere virüs, ağız, burun veya göz mukozası yoluyla bulaşmaktadır. Ayrıca hasta bireylerden dışarı çıkan bu damlacıkları soluyan sağlıklı bireylerin de hastalandığı bilinmektedir. Kişilerin ne kadar süreyle taşıyıcı olduklarına dair kesin bir veri bulunmamakla birlikte; hiçbir belirti göstermeyen kişilerin de virüsü yaydığ 1 gözlemlenmiştir (WHO, 2020a; T.C. Sağlık Bakanlığı, 2020). Koronavirüsün insandan insana bulaşması nedeniyle, korunmak amacıyla bireylerin kişisel hijyen önlemlerini arttırması ve yakın temas içeren ortamlardan kaçınması gerekmektedir (Karataş, 2020). Bu nedenle 
salgının yaşandığı ülkelerde ve Türkiye'de hükümet tarafından birçok önlem alınmıştır. Günümüzde halen virüsün etkisinin devam ettiği, her gün yeni vakaların ve vefat eden bireylerin olduğu Covid19 sürecinde koronavirüsten korunmak amaciyla sosyal mesafe kuralı, karantina, sokağa çıkma yasağı, seyahat kısıtlamaları, bazı kurumların ve iş yerlerinin kapatılması, esnek çalışma saatleri, uzaktan eğitim ve evden çalışma sistemine geçilmesi bu süreçte alınan önlemlerdendir. Tüm dünyada olduğu gibi Türkiye'de de birçok alanda değişime veya dönüşüme neden olan Covid-19 salgını en başta sağlık, sosyo-ekonomik, psikolojik açılardan bireylerin davranışlarını, yaşam tarzlarını, alışkanlıklarını ve dolayısıyla yaşantılarını etkilemektedir.

Taylor (2019) küresel çaptaki salgınların beş önemli psiko sosyal durumu ortaya çıkardığını ve bunlardan ilkinin salgının bulaşma ve ölüm riskinin olması nedeniyle insanların panik içinde alışverişe yönelmesi, gıda ve temizlik malzemesi stoklamaya başlaması olduğunu belirtmektedir. Meyer (2020) Covid-19 salgınının tüm dünyaya hızlı bir şekilde yayılması ve pandemi olarak ilan edilmesiyle, bireylerin daha fazla alışveriş yaparak stok yapma eğiliminde olduklarını ifade etmektedir. Bu süreçte bireylerin çoğunlukla kişisel hijyen amaçlı el sabunu, el dezenfektanı ve cerrahi maske gibi tıbbi malzemeler ile tuvalet kâğıdı ve ekmek gibi ürünlere daha fazla talep gösterildiği belirtilmektedir (Meral, 2020; Meyer, 2020).

Covid-19 salgınından korunmak için WHO ve T.C Sağlık Bakanlığı'nın sıklıkla üzerinde durduğu en önemli önlem hijyendir. Özellikle ellerin s1k s1k ve en az 20 saniye boyunca hijyenik el yıkama aşamalarına göre yıkanması gerektiği belirtilmiştir. Ayrıca hasta insandan çıkan damlacıkların, kapı kolu, masa ve benzeri nesnelere de kolayca yerleşebildiği bilindiğinden (WHO, 2020; T.C. Sağlık Bakanlığ1, 2020); uzmanlar, tüm yüzeylere, eşyalara, alışverişte alınan ürünlere temasa dair de uyarılarda bulunmaktadır. Bireylerin temizlik maddelerine olan ilgisinin artışı, özellikle kişisel ve genel hijyeni sağlamak amacıyla çok miktarda satın alımıyla ilgili olarak yapılan çalışmalar incelendiğinde; Yavuz (2020) kişisel bakım ürünlerine talebin \%10 oranında arttığını, Torun-Kayabaşı (2020) ise temizlik malzemesi, kişisel hijyen ürünlerinde satışların arttığı, bu alandaki üreticilerin pandemi döneminde büyük bir gelir artışının yaşandığını belirtmektedir. Anadolu Ajansının yaptığı bir haberde; koronavirüsün bulaşma yollarının bilindiği ve bunun önüne geçilmesi için sağlığı koruyan ve sağlık güvenliği maddelerine olan talebin hızla arttı̆̆ı, salgının Türkiye'de görülmeye başladığ 1 9-16 Mart 2020 haftasında, bir önceki haftaya göre kolonya satışının 34 kat, steril eldivenin 19 kat, el dezenfektanının 10 kat, sabunun 4 kat, medikal maskenin 4 kat, tuvalet kâğıdı satışının ise 3,5 kat arttığı ifade edilmiştir (Günyol, 2020). Benzer şekilde Google Trend verileri incelendiğinde; salgının ilk haftasında kolonyaya gösterilen ilginin \%100'e ulaştığ1 görülmüştür. Salgın sürecinde sokağa çıkma yasakları veya bireylerin virüse yakalanma endişeleri gibi nedenlerle e-ticareti tercih etme oranlarının arttığı bilinmektedir (Güven, 2020). Nielsen'in (2020) "Koronavirüsün Global Tüketiciler Üzerindeki Etkileri” araştırmasında da ülkemizde salgın görülmeye başladıktan sonra bireylerin \%41'i internetten yaptıkları alışverişte gıda, içecek ve ev temizlik ürünlerini daha fazla aldığı sonucuna varılmıştır. Kısmi sokağa çıkma yasağının uygulandığı veya insanların büyük kısmının gönüllü olarak kendisini karantina altına aldığı düşünüldüğünde; bireylerin sağlıkla ilgili kaygılarının artarak hijyen, temizlik ve temasla ilgili daha fazla önlem almaları ile gıda ve temizlik ürünlerinin tüketiminin artması beklenen bir durumdur (Karataş, 2020).

Bireylerin kendini güvende tutma hissini ve güvence altına almak için değişen koşullara uyum sağlamaya yönelik birçok davranış değişiklikleri yaşanmaktadır. Torun-Kayabaşı (2020) çalışmasında bireylerin ekmeğini ve bazı yiyeceklerini evde kendilerinin yaptığını ifade etmektedir. Nitekim Yavuz'un (2020) çalışmasında da kuru mayaya olan talebin \%8-15 artığını, ekmeğe olan talebin ise \%35 oranında azalmış olduğu belirlenmiştir. Ipsos Araştırma Şirketi'nin Mart ayı Hane Tüketim Araştırması'na göre Şubat ayında önceki döneme göre un alışverişinin \%98, maya alışverişinin de \%80 arttığ 1 tespit edilmiştir (TRT Haber, 2020). 
Evden çalışma sistemine geçilmesiyle çalışan kadınların ev içi faaliyetlere ayırdıkları zaman ve çabada da değişiklik yaşanmıştır. Akbaş-Zeybekoğlu ve Dursun (2020) salgın sürecinde çalışma yaşamını evden sürdüren annelerin araştırma kapsamına alındığı çalışmasında; salgın öncesinde ev içi faaliyetlerde yardım aldıklarınına fakat salgın sürecinde bu faaliyetleri kendilerinin yapmak zorunda kaldığına, bunun yanı sıra daha fazla ve dikkatli bir şekilde hijyen sağlama çabalarının olduğuna değinmiştir. Benzer şekilde Bozkurt (2020) Covid-19 salgınıla birlikte ortaya çıan gelişmeleri belirlemek amacıyla 5300 kişiyle gerçekleştirdiği çalışmasında da; salgınla birlikte evden/online çalışan kadınların, bu süreçte çocuk bakımı ve temizlik işlerine ilişkin hizmet aldığı yardımcılarını kaybettiği sonucuna varılmıştır. Ayrıca hem hazır yemek sektörünün yayınlanan genelge ile belli bir süre kapalı kalması hem de bireylerin hijyene ilişkin farkındalıklarının artması nedeniyle dışarıdan yemek sipariş etme davranışlarının azaldığı düşünülmektedir. Nitekim Bozkurt (2020) da dışarıdan yemek sipariş imkânlarının büyük ölçüde ortadan kalktığını çalışmasında belirtmektedir.

Yaşanan tüm bu davranış değişiklikleri düşünüldüğünde; Covid-19 salgın sürecinde bireylerin hijyene yönelik değişen davranışlarını belirlemek amacıyla bir ölçek geliştirilmesi amaçlanmıştır.

\section{Yöntem}

\section{Veri Toplama Yöntem ve Araçları}

Ölçek geliştirmenin ilk aşaması olan madde havuzu oluşturmak amacıyla başta Dünya Sağlık Örgütü (WHO) ve T.C Sağlık Bakanlığı'nın korona virüse karşı alınacak önlemler ve kuralları ile ilgili alan yazın incelenmiştir. Korona virüse karşı alınacak kişisel ve genel hijyen tedbirlerine yönelik davranışlar belirlenerek ölçekte kullanılabilecek 50 madde yazılııştır. Oluşturulan maddeler alanında uzman 6 öğretim görevlisine önce çalışmanın konusu hakkında bilgi verilerek görüşlerine sunulmuştur. Uzmanlardan gelen dönüşler sonrasında 10 madde çıkarılmış, bazı maddelerde ise düzeltmeler yapılmıştır. Böylece 40 maddelik 5 'li derecelendirme ile 5 puan 'Her zaman', 1 puan 'Hiçbir zaman' olarak deneme formu oluşturulmuştur. Bununla birlikte; bireylerin demografik (cinsiyet, yaş, medeni durum, eğitim durumu, salgın amaciyla sosyal izolasyonun sağlandığı zamanlarda çalışma durumu, çalıştıysa diğer insanlarla fiziksel etkileşimde bulunma durumu, ailenin toplam aylık geliri, yaşadığı yer) ve salgın dönemine ilişkin bazı bilgilerini belirlemeye yönelik sorulara (salgın döneminde kişisel ve genel temizlik için temizlik malzemelerine ayırdığı aylık bütçede artış durumu, salgın öncesinde ve salgın döneminde kişisel ve genel temizlik için temizlik malzemelerine ayırdığı aylık ortalama bütçe, evde yaşayan toplam kişi sayısı, ailede 65 yaş ve üstü ya da 20 yaş altı, kronik rahatsızlığı (tansiyon, diyabet, kalp rahatsızlıkları) ve Covid-19 tanısı alan bireyin olma durumu ile salgın döneminde görsel ve yazılı basında yayınlanan kamu spotlarının bireyin kişisel hijyen önlemleri hakkındaki bilgisine etkisi) yer verilmiştir. Oluşturulan deneme formu 20 bireye pilot olarak uygulanmış, ankete son şekli verilerek uygulamaya hazır hale getirilmiştir.

Ölçeğin yapı geçerliliğini belirlemek amacıyla farklı sosyo-ekonomik özelliklere sahip basit rastgele örnekleme yöntemiyle belirlenen 837 birey çalışma kapsamına alınmıştır. Çevrim içi olarak hazırlanan anket formunun ilk sayfasında gönüllü katılım formu yer almış, araştırmanın amacından bahsedilmiş, araştırma formuyla elde edilen bilgilerin bilimsel amaçla kullanılacağı, bilimsel etik kuralları çerçevesinde gizlilik içinde değerlendirileceği ve başka bir amaçla kullanılmayacağ belirtilmiş, bu şartları kabul ettikleri takdirde anket formuna erişimleri sağlanmıştır.

Çalışmaya başlamadan önce Hacettepe Üniversitesi Etik Komisyonu'ndan (35853172-200 sayılı karar) izin alınmıştır. 


\section{Verilerin Değerlendirilmesi ve Analizi}

Araştırmanın verileri toplandıktan sonra tanımlayıcı bilgiler sayı ve yüzde şeklinde tablolaştırılmış, ölçeğin yapı geçerliliğinin test edilebilmesi için Doğrulayıcı Faktör Analizi (DFA) yapılmıştır. İstatistiksel analizler için SPSS v.23.0 ve SPSS AMOS Graphics v23.0 programları kullanılmıştır.

\section{Bulgular}

Çalışmaya katlan bireylerin \%74,6'sı kadın \%25,4'ü erkektir. Katılımcıların \%73,4'ü evli olup, \%36,9'u 35-49 yaş aralığındadır. Ailenin toplam aylık geliri açısından katılımcıların \%63,3'ü 6000 TL ve üzerinde geliri olduğunu belirtmekle birlikte; katılımcıların yaklaşık yarısı $(\% 52,3)$ lisans mezunudur. Salgın döneminde alınan önlemler gereği çalışmaya katılan bireylerin çalışma durumları incelendiğinde; \%24,9'unun evden çalıştığı, \%17,6'sının ise bazı günler işe gidip bazı günler çalıştığ1 belirlenmiştir. Ayrıca salgın döneminde evden çalışanlar dışında çalıştığını belirten katılımcıların $(\mathrm{n}=252) \% 52,6$ 's1 işi gereği diğer insanlarla fiziksel etkileşimde bulunduğunu belirtmiştir (Tablo 1).

Tablo 1: Çalışmaya Katılan Bireylerin Demografik Özelliklerine Göre Dağılımı

\begin{tabular}{|c|c|c|c|}
\hline Değișkenler & Gruplar & $\mathbf{n}$ & $\%$ \\
\hline \multirow{2}{*}{ Cinsiyet } & Kadın & 624 & 74,6 \\
\hline & Erkek & 213 & 25,4 \\
\hline \multirow{2}{*}{ Medeni Durum } & Evli & 614 & 73,4 \\
\hline & Bekar & 223 & 26,6 \\
\hline \multirow{4}{*}{ Yaş } & 34 yaş ve altı & 216 & 25,8 \\
\hline & $35-49$ & 309 & 36,9 \\
\hline & $50-64$ & 252 & 30,1 \\
\hline & 65 yaș ve üstü & 60 & 7,2 \\
\hline \multirow{4}{*}{ Ailenin toplam aylık geliri } & 2324 TL ve daha az & 33 & 3,9 \\
\hline & 2325-3999 TL & 111 & 13,3 \\
\hline & 4000-5999 TL & 163 & 19,5 \\
\hline & 6000 TL ve üzeri & 530 & 63,3 \\
\hline \multirow{4}{*}{ Eğitim Durumu } & Lise ve daha az & 114 & 13,6 \\
\hline & Ön lisans & 92 & 11,0 \\
\hline & Lisans & 438 & 52,3 \\
\hline & Lisans üstü & 193 & 23,1 \\
\hline \multirow{11}{*}{$\begin{array}{l}\text { Salgına ilişkin alınan } \\
\text { önlemler doğrultusunda } \\
\text { çalışma durumu }\end{array}$} & Çalışmıyor & 199 & 23,8 \\
\hline & Emekli & 146 & 17,4 \\
\hline & Her gün işe gittim & 79 & 9,4 \\
\hline & Evden çalıştım & 208 & 24,9 \\
\hline & $\begin{array}{l}\text { Bazı günler işe gidip, } \\
\text { bazı günler evden calıstım. }\end{array}$ & 147 & 17,6 \\
\hline & Salgın döneminde işsiz kaldım. & 6 & 0,7 \\
\hline & Kendi işim, çalışmaya devam ettim & 5 & 0,6 \\
\hline & Kendi ișim, ancak kapalıydı/çalıșmadım & 12 & 1,4 \\
\hline & Kısa çalıșma ödeneğinden yararlandım & 18 & 2,2 \\
\hline & İdari izinliydim & 13 & 1,6 \\
\hline & Diğer (doğum izni, ücretsiz izin) & 4 & 0,5 \\
\hline Toplam & & 837 & 100,0 \\
\hline
\end{tabular}

Katılımcıların Covid-19 döneminde önemli olduğu düşünülen bazı bireysel ve ailesel bilgilerinin incelendiği Tablo 2'ye göre; katılımcıların \%61,8'inin ailesinde 20 yaş altı veya 65 yaş ve üzeri bireylerin yaşadığ $1, \% 52,0$ 'sinin kendisinde ya da ailesinde kronik rahatsızlı̆̆ın olduğu, \%1,0'inin (n=8) ailesinde Covid-19 tanısı alan bireylerin bulunduğu sonucuna varılmıştır. Covid-19 salgınının ülkemizde görülmeye başlamasıyla salgından korunmak için kişisel hijyenin önemini vurgulayan görsel ve yazılı basında yayınlanan kamu spotlarının mevcut hijyen bilgisini artırdığını 
belirtenler katılımcıların \%90,7'sini oluşturmaktadır. Ayrıca katılımcıların \%74,7'si salgınla birlikte kişisel ve genel temizlik için aylık ayırdığı bütçede artış olduğunu ifade etmiştir.

Tablo 2: Çalışmaya Katılan Bireylerin Covid-19 Salgınına İlişkin Bazı Bilgilerinin Dağılımı

\begin{tabular}{llcc}
\hline Değișkenler & Gruplar & n & \% \\
\hline Ailede 20 yaş altı ve 65 yaş üstü & Evet & 517 & 61,8 \\
bireyin yaşama durumu & Hayır & 320 & 38,2 \\
\hline Ailede kronik rahatsızlık olan bireyin & Evet & 435 & 52,0 \\
varlığı & Hayır & 402 & 48,0 \\
\hline \multirow{2}{*}{ Ailede Covid-19 tanısı olma durumu } & Evet & 8 & 1,0 \\
& Hayır & 829 & 99,0 \\
\hline Kamu spotlarının kişisel hijyen & Evet & 759 & 90,7 \\
önlemlerine ilişkin bilgiye etkisi & Hayır & 78 & 9,3 \\
\hline Toplam & & $\mathbf{8 3 7}$ & $\mathbf{1 0 0 , 0}$ \\
\hline
\end{tabular}

Ölçeğin iç güvenirlik katsayıları SPSS v.23.0 programı kullanılarak hesaplanmıştır. 27 maddeden oluşan ölçeğin Cronbach alpha katsayısı \%95 güven aralığında değerlendirilmiş ve 0,908 olarak bulunmuştur. Ölçeğin alt boyutlarının iç güvenirlik katsayıları ise Tablo.3'te verilmiştir. Alpar (2011, s.815) iç güvenirlik katsayısının .80 ile 1.00 arasında olmasını "yüksek derecede güvenilir", .60 ile .79 arasında olmasını ise "oldukça güvenilir" şeklinde açıklamaktadır. Buna göre; Covid-19 Hijyen Ölçeği “yüksek derecede güvenilir”, ölçeğin tüm alt boyutları ise "oldukça güvenilir" olduğu belirlenmiştir.

Tablo 3: Covid-19 Hijyen Ölçeği ve Alt boyutlarının Tanımlayıcı İstatistikleri ve İç Güvenirlik Katsayıları

\begin{tabular}{lccccc}
\hline Alt boyutlar & Ort. & ss & $\begin{array}{c}\text { Çarpıklık } \\
(\mathbf{S . E}=, \mathbf{0 8 5})\end{array}$ & $\begin{array}{c}\text { Basıklık } \\
(\mathbf{S . E}=\mathbf{1 6 9})\end{array}$ & $\boldsymbol{\alpha}$ \\
\hline Salgınla Değişen Hijyen Davranışları & 23,08 & 4,779 & 0,737 & 0,108 & 0.749 \\
\hline Ev Hijyeni & 15,68 & 3,001 & $-0,469$ & $-0,342$ & 0.690 \\
\hline Sosyal Mesafe ve Maske Kullanımı & 18,43 & 2,149 & $-1,989$ & 5,072 & 0.688 \\
\hline Alışveriş Hijyeni & 20,38 & 4,367 & $-0,924$ & 0,141 & 0.742 \\
\hline El Hijyeni & 22,75 & 2,844 & $-1,727$ & 3,338 & 0.702 \\
\hline Dışarıdan Eve Gelindiğinde Hijyen & 11,99 & 2,770 & $-1,058$ & 0,738 & 0.698 \\
\hline Covid-19 Hijyen Ölçeği & 112,31 & 15,467 & $-0,915$ & 0,697 & 0.908 \\
\hline
\end{tabular}

Ölçek için alt faktörlere uygun sorular belirlenerek her bir ölçekte gerekli yüklenmenin başarılı bir şekilde olup olmadığını belirlemek amacıyla Doğrulayıcı Faktör Analizi (DFA) uygulanmıştır. İlgili analiz, ölçeğin yapı geçerliliğinin test edilmesi amacıyla SPSS AMOS Graphics v23.0 programı kullanılarak yapılmıştır. Maddeler ve karşılık gelen alt boyutlar arasındaki ilişki yapısı Şekil 1.'de verilmiştir. Daha sonra alan yazında en çok bilinen model uyum kriterlerinden $\chi^{2 / d f}$, uyum iyiliği indeksi (GFI), düzeltilmiş uyum iyiliği indeksi (AGFI) ve yaklaşık ortalamaların karekökü (RMSEA) değerleri belirlenmiştir (Di Fabio ve Blustein, 2016, s.1119).

Elde edilen analiz sonucunda bazı maddelerin hata değerleri bulunmuş oldukları alt ölçek içindeki başka maddelerin hata değerleriyle kovaryansa sahiptir. Bu durum varsayım bozulumuna sebep olduğundan, bu problem giderilmiştir. Hata terimleri kovaryanslı olan maddeler silindiğinde ve modifikasyon göstergelerini inceleyerek yapılan düzeltmelerden sonra, tanımlanan yapının ölçek olarak son versiyonu Şekil 2'de (sağ) verilmiştir. 

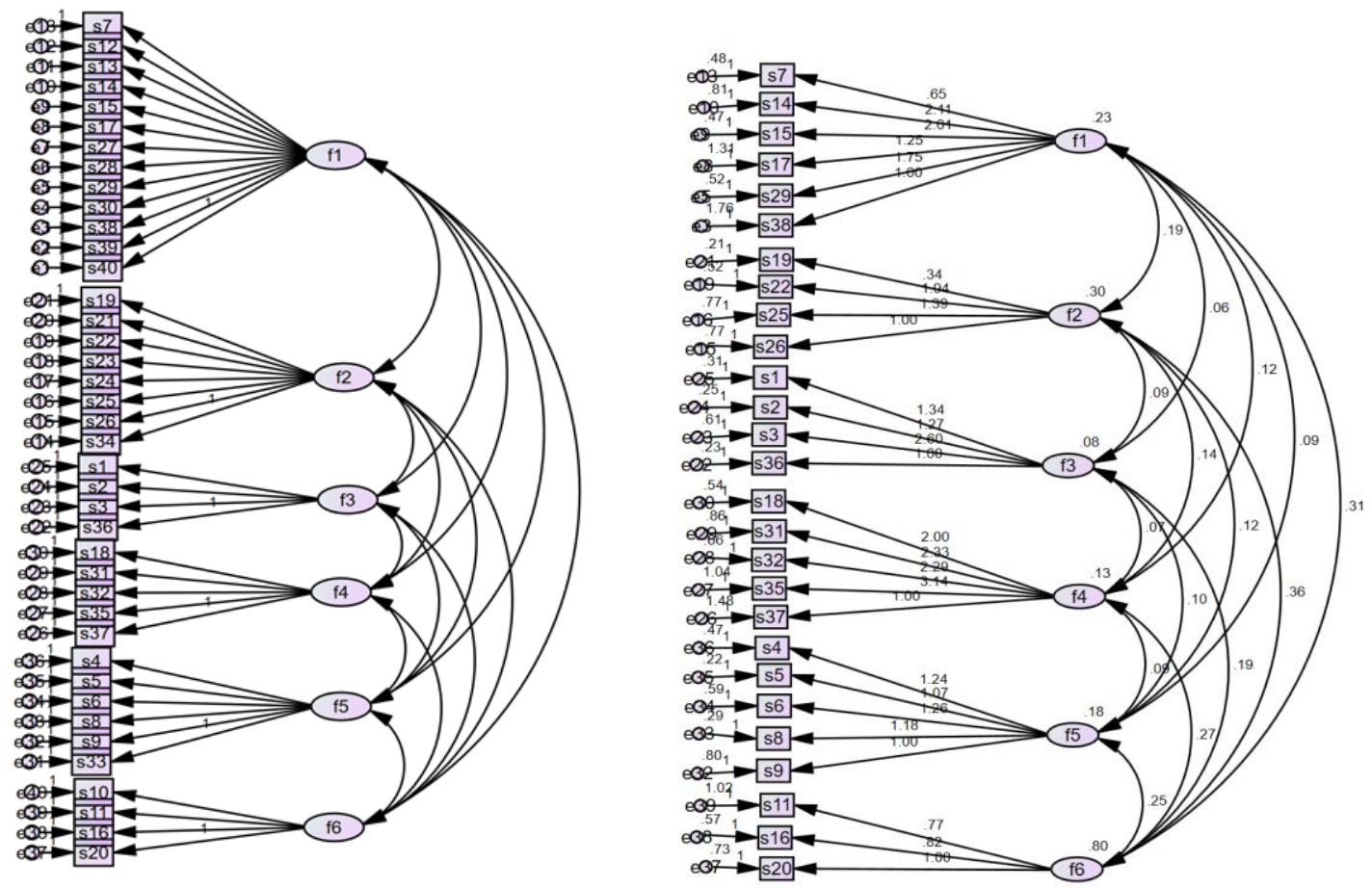

Şekil 1: DFA Grafiği (40 madde)

Şekil 2: DFA Grafiği (27 madde)

Yapılan Doğrulayıcı Faktör Analizi sonucunda elde edilen bulgulara göre $\chi 2 / \mathrm{df}=4.509$, $p<.001$, GFI $=.885, \mathrm{AGFI}=.859$ ve RMSEA $=.065$ değerlerine ulaş1lmıştır. $\chi 2 /$ df oranının 2 'nin altında olması iyi uyumu, 5 'in altında olması ise kabul edilebilir uyumu gösterirken (Jabeen ve Hamid, 2019; Kline, 2010; Şimşek, 2007); RMSEA değerinin .05'ten küçük veya eşit olması iyi bir uyumu, .05 ve .08 arasinda olması yeterli uyumu, .08 ve .10 arasinda ise zayıf bir uyumu göstermektedir. AGFI ve GFI değerleri ise .95 üzeri mükemmel uyumu, .90 ve üzeri iyi bir uyumu göstermektedir (Hu ve Bentler, 1999; Schumacker ve Lomax, 1996). Değerler incelendiğinde; model uyumunu gösteren $\mathrm{GFI}=.885<.90$ ve $\mathrm{AGFI}=.859<.90$ beklenen değerlerin biraz altında olmasına rağmen ölçek modelinin yeterli düzeyde uyumlu olduğu sonucuna varılmıştır.

Parametrelerin regresyon tahminleri Tablo 4'te verilmiştir. Tabloya göre, her bir madde yer aldığı alt boyutlar açısından istatistiksel olarak anlamlı bulunmuştur. Tüm katsayılar Şekil.2'de de gösterilmektedir.

Faktörlere karşılık gelen maddelerin regresyon katsayı ağırlıkları Tablo 4'te verilmiştir. Elde edilen bilgilere göre ilk faktör için en anlamlı madde s15 sorusudur "Daha çok çamaş̧ır yıkıyorum." ve istatistiksel anlamlılık tüm maddeler tarafindan sağlanmıştır. Aynı şekilde tüm faktörlerdeki maddelerin faktörlere olan etkisinin istatistiksel olarak anlamlı olduğu görülmüştür. Faktör 2'de en önemli maddenin s22 "Evde kullandığımız tüm kapl, dolap ve pencere kollarını her gün dezenfekte ediyorum." olduğu görülürken faktör 3 için, s3 "Maske taktıktan sonra maskeye dokunduysam ellerimi dezenfekte ediyorum."; faktör 4 için s32 "Satın alınan yiyecek ve içeceklerin dış yüzeylerini siliyorum/yıkıyorum."; faktör 5 için s5 "Ellerimi siks slk su ve sabun ile en az 20 saniye boyunca yıkıyorum." ve faktör 6 için s16 "Dışarıdan eve geldiğimde kıyafetlerimi hemen havalandırıyorum." sırasıyla ilgili faktörlerin en önemli maddeleridir. Diğer maddelere karşılık gelen regresyon ağırlıklı katsayıları takip edilebilir. 
Tablo 4: Faktörlere Karışlık Gelen Regresyon Ağırlıkları

\begin{tabular}{|c|c|c|c|c|c|c|}
\hline & & & Estimate & S.E. & C.R. & $\mathbf{P}$ \\
\hline s38 & $<--$ & f1 & 1.000 & & & \\
\hline s29 & $<---$ & f1 & 1.749 & .189 & 9.262 & $* * *$ \\
\hline $\mathbf{s 1 7}$ & $<---$ & $\mathrm{f} 1$ & 1.252 & .156 & 8.009 & $* * *$ \\
\hline s15 & $<---$ & f1 & 2.008 & .214 & 9.376 & $* * *$ \\
\hline s14 & $<---$ & f1 & 2.110 & .229 & 9.232 & $* * *$ \\
\hline s7 & $<---$ & f1 & .651 & .086 & 7.581 & $* * *$ \\
\hline s26 & $<--$ & $\mathrm{f} 2$ & 1.000 & & & \\
\hline s25 & $<---$ & $\mathrm{f} 2$ & 1.388 & .106 & 13.103 & $* * *$ \\
\hline s22 & $<---$ & $\mathrm{f} 2$ & 1.937 & .135 & 14.391 & $* * *$ \\
\hline s19 & $<---$ & f2 & .345 & .038 & 9.084 & $* * *$ \\
\hline s36 & $<---$ & f3 & 1.000 & & & \\
\hline s3 & $<---$ & f3 & 2.596 & .204 & 12.737 & $* * *$ \\
\hline s2 & $<---$ & f3 & 1.267 & .108 & 11.755 & $* * *$ \\
\hline s1 & $<---$ & f3 & 1.342 & .116 & 11.537 & $* * *$ \\
\hline s37 & $<---$ & $\mathrm{f} 4$ & 1.000 & & & \\
\hline s35 & $<---$ & $\mathrm{f} 4$ & 3.141 & .416 & 7.554 & $* * *$ \\
\hline s32 & $<---$ & $\mathrm{f} 4$ & 2.290 & .305 & 7.507 & $* * *$ \\
\hline s31 & $<---$ & $\mathrm{f} 4$ & 2.327 & .313 & 7.435 & $* * *$ \\
\hline s18 & $<---$ & $\mathrm{f} 4$ & 2.001 & .267 & 7.491 & $* * *$ \\
\hline s9 & $<---$ & f5 & 1.000 & & & \\
\hline s8 & $<---$ & f5 & 1.185 & .111 & 10.624 & $* * *$ \\
\hline s6 & $<---$ & f5 & 1.262 & .127 & 9.916 & $* * *$ \\
\hline s5 & $<---$ & f5 & 1.067 & .100 & 10.688 & $* * *$ \\
\hline s4 & $<---$ & f5 & 1.238 & .122 & 10.182 & $* * *$ \\
\hline s20 & $<---$ & f6 & 1.000 & & & \\
\hline s16 & $<---$ & f6 & .817 & .045 & 18.043 & $* * *$ \\
\hline s11 & $<---$ & f6 & .766 & .052 & 14.704 & $* * *$ \\
\hline
\end{tabular}

Ölçeğin alt boyutları arasındaki ilişki incelenmiş; boyutlar arasındaki korelasyon katsayıları Tablo.5'te sunulmuştur. Analiz sonucuna göre tüm alt boyutların birbirleri ile olumlu ve istatistiksel olarak anlamlı ilişki içinde olduğu belirlenmiştir. En düşük ilişki aynı yönde \%37,3 ile "Sosyal Mesafe ve Maske Kullanımı" ile "Salgınla Değişen Hijyen Davranışları" faktörleri arasında iken en yüksek iliş̧ki ise aynı yönlü \%61,1 ile "Alışveriş Hijyeni”" ile "Dışarıdan Eve Gelindiğinde Hijyen Faktörleri" arasındadır. Faktörler arasındaki anlamlı ve orta düzeyin üstündeki ilişki sonucunda, araştırmaya katılan bireylerin pandemi sürecindeki davranışlarını ölçebilecek faktör yapısının kurulabildiği görülmektedir.

Tablo 5: Faktörler Arası Korelasyon Katsayıları

\begin{tabular}{|c|c|c|c|c|c|c|}
\hline & $\begin{array}{c}\text { Salgınla } \\
\text { Değişen Hijyen } \\
\text { Davranışları }\end{array}$ & $\begin{array}{c}\text { Ev } \\
\text { Hijyeni }\end{array}$ & $\begin{array}{c}\text { Sosyal Mesafe } \\
\text { ve Maske } \\
\text { Kullanımı }\end{array}$ & $\begin{array}{c}\text { Alışveriş } \\
\text { Hijyeni }\end{array}$ & $\begin{array}{c}\text { El } \\
\text { Hijyeni }\end{array}$ & $\begin{array}{c}\text { Dışarıdan Eve } \\
\text { Gelindiğinde } \\
\text { Hijyen }\end{array}$ \\
\hline $\begin{array}{c}\text { Salgınla } \\
\text { Değişen Hijyen } \\
\text { Davranışları }\end{array}$ & & $0.580^{*}$ & $0.373^{*}$ & $0.595^{*}$ & $0.390^{*}$ & $0.570^{*}$ \\
\hline Ev Hijyeni & & & $0.417^{*}$ & $0.557^{*}$ & $0.422^{*}$ & $0.519^{*}$ \\
\hline $\begin{array}{c}\text { Sosyal Mesafe } \\
\text { ve Maske } \\
\text { Kullanımı }\end{array}$ & & & $0.519^{*}$ & $0.583^{*}$ & $0.517^{*}$ \\
\hline $\begin{array}{c}\text { Alışveriş } \\
\text { Hijyeni }\end{array}$ & & & & $0.468^{*}$ & $0.611^{*}$ \\
\hline El Hijyeni & & & & & & $0.499^{*}$ \\
\hline
\end{tabular}

$* \mathrm{p}<0.01$ 


\section{Sonuç ve Öneriler}

$\mathrm{Bu}$ çalışmada; Covid-19 salgın sürecinde bireylerin hijyen davranışlarını belirlemek amacıyla "Salgınla Değiş̧en Hijyen Davranışları", "Ev Hijyeni", "Sosyal Mesafe ve Maske Kullanımı", "Alışveriş Hijyeni", "El Hijyeni" ve "Dışarıdan Eve Gelindiğinde Hijyen" olmak üzere 6 alt boyuttan oluşan "Covid-19 Hijyen Ölçeğì" geliştirilmiştir.

Ölçek, bireylerin salgından korunmak, korona virüsün bulaşma yollarını en aza indirmek amacıyla alınan kişisel ve genel hijyen önlemlerine ilişkin davranışları içeren 27 maddeden (C. alpha: .908) oluşmaktadır. Ölçekten alınabilecek en düşük puan 27, en yüksek puan ise 135 olup, alınan yüksek puan bireylerin salgından korunmak amacıyla kişisel ve genel hijyene ilişkin davranış sergileme düzeyinin yüksek olduğunu, hijyen önlemlerine önem verdiğini göstermektedir.

"Salgında Değişen Hijyen Davranışları" alt boyutu, bireylerin salgın öncesine göre daha fazla sergiledikleri bazı hijyen davranışlarını içeren 6 maddeden (C. alpha: .749) oluşmaktadır. "Daha çok çamaşır ylkiyorum.", "Ev temizliğine daha çok zaman aylrıyorum.", "Ekmek vb. ürünleri evde yapıyorum. "gibi maddeler yer almaktadır. Bu alt boyuttan alınabilecek en düşük puan 6 , en yüksek puan ise 30 'dur. Alınan yüksek puan, salgınla birlikte bireylerin salgından korunmak amacıyla hijyene ilişkin yeni davranışlara önem verdiğini ve benimsediğini, mevcut davranışlarını ise daha sık sergilediğini göstermektedir.

"Ev hijyeni" alt boyutu ise bireylerin salgından korunmaya yönelik olarak evin genel hijyenini sağlamaya ilişkin 4 maddeyi (C. alpha: .690) içermektedir. "Evde kullandiğımız tüm kapı, dolap ve pencere kolların her gün dezenfekte ediyorum.", "Odalarl düzenli olarak havalandırıyorum." gibi maddeler yer almaktadır. Bu alt boyuttan alınabilecek en düşük puan 4, en yüksek puan ise 20'dir. Bu boyuta ilişkin yüksek puan, bireylerin salgından korunmak amacıyla ev hijyenine ilişkin davranış sergileme düzeyinin yüksek olduğunu, ev hijyenine daha fazla önem verdiğini ifade etmektedir.

"Sosyal Mesafe ve Maske Kullanımı" alt boyutu bireylerin salgından korunmak amaciyla diğer kişilerle sosyal mesafeyi koruma ve maske kullanımına ilişkin 4 maddeden (C. alpha: .688) oluşmaktadır. "Kalabalık ortamlarda sosyal mesafeyi koruyorum.", "Dışarı çıkarken her zaman maske takıyorum." maddelerden birkaçına örnek olarak gösterilebilir. Bu alt boyuttan alınabilecek en düşük puan 4, en yüksek puan ise 20'dir. Alınan yüksek puan, bireylerin salgından korunmak için sosyal mesafe ve maske kullanımına önem verdiği ve bunun için çaba gösterdiğini ifade etmektedir.

“Alışveriş Hijyeni” alt boyutunda bireylerin alışveriş esnasında ve sonrasında koronavirüsün etkilerini en aza indirmek amacıyla aldıkları önlemlere ilişkin 5 madde (C. alpha: .742) yer almaktadır. "Marketten satın aldıklarımı taşıdığım plastik poşetleri eve girmeden önce sabunlu bez veya dezenfektan ile siliyorum.", "Alışveriş yaparken nakit para yerine kredi kartımin temassiz özelliğini kullanıyorum." bu boyuttaki maddelerdendir. Alt boyuttan alınabilecek en düşük puan 5, en yüksek puan ise 25 olup; alınan yüksek puan bireylerin koronavirüs bulaş yollarını en aza indirmek için alışveriş esnasında ve sonrasında hijyen önlemleri aldıklarını göstermektedir.

"El Hijyeni" alt boyutu ise koronavirüsten korunmanın en etkili yolu olan el temizliği ve hijyenine ilişkin 5 maddeden (C. alpha: .702) oluşmaktadır. "Ellerimi slk slk su ve sabun ile en az 20 saniye boyunca ylkiyorum.", "Ellerimi tek kullanımlı kâğıt havlu veya kendime ait bir havlu ile kuruluyorum." şeklinde maddeler bu alt boyutta yer almaktadır. Alt boyuttan alınabilecek en düşük puan 5, en yüksek puan ise $25^{\prime}$ tir ve alınan yüksek puan bireylerin salgından korunmak amaciyla el hijyenine ilişkin davranış sergileme düzeyinin yüksek olduğunu, el hijyenine son derece dikkat edip, özen gösterdiğini ifade etmektedir.

Bir diğer alt boyut ise "Dışarıdan Eve Gelindiğinde Hijyen"dir. Koranavirüsten korunmak amacıyla iş, alışveriş ya da farklı amaçlarla dışarı çıkan ve kalabalık ortamlara giren bireylerin eve geldiğinde aldığı önlemlere ilişkin 3 madde (C. alpha: .698) yer almaktadır. "Dışarıdan eve geldikten 
sonra duş alıyorum.", "Dışarıdan eve geldiğimde klyafetlerimi hemen havalandırıyorum.", "Eve geldiğimde çanta, cüzdan, anahtarlı ve cep telefonumu dezenfekte ediyorum." alt boyutta yer alan maddelerdir. Alt boyuttan alınabilecek en düşük puan 3, en yüksek puan ise $15^{\prime}$ tir ve alınan yüksek puan bireylerin salgından korunmak amacıyla dışarıdan eve geldikten sonra yüksek düzeyde hijyen kurallarını uyguladığını göstermektedir.

Covid-19 salgın döneminde bireylerin kişisel ve genel hijyene yönelik davranışlarını belirlemek amacıyla hazırlanan bu ölçeğin yapı ve kapsam geçerliliği göz önüne alındığında, ölçeğin konuyla ilgili çalışmalarda kullanılabilir olduğu düşünülmektedir.

\section{Kaynakça}

Akbaş- Zeybekoğlu, Ö. ve Dursun, C. (2020). Koronavirüs (Covid-19) pandemisi sürecinde özel alanına kamusal alanı sığdıran çalışan anneler. Avrasya Sosyal ve Ekonomi Araştırmaları Dergisi, 7(5), 78-94.

Alpar, R. (2011). Uygulamalı Çok Değişkenli İstatistiksel Yöntemler. Detay Yayınc1lı.

Bozkurt, V. (2020, Nisan 24). Salgının belirsizliği huzursuzluğu artırdı. https://www.hurriyet.com.tr/amp/yazarlar/sibel-bagci-uzun/salginin-belirsizligihuzursuzlugu-artirdi-41501744 Erişim Tarihi: 08.06.2020.

Di Fabio, A. and Blustein, D. L. (2016). From meaning of working to meaningful lives: The challenges of expanding decent work. Frontiers in psychology, 7, 1119. doi: 10.3389/fpsyg.2016.01119

Google Trend (2020). https://trends.google.com/trends/explore?q=kolonya\&geo=TR. Erişim Tarihi: 08.06.2020.

Günyol, A. (2020, Mart 20). Koronavirüs ile birlikte türkiye'de e-ticaret satışları arttı. https://www.aa.com.tr/tr/ekonomi/koronavirus-ile-birlikte-turkiyede-e-ticaret-satislari-artti/1772734 Erişim Tarihi: 08.06.2020.

Güven, H. (2020). Covid-19 sürecinde e-ticaret sitelerine yöneltilen müşteri şikâyetlerinin incelenmesi. Turkish Studies, 15(4), 511-530. https://dx.doi.org/10.7827/TurkishStudies.44354

Hu, L. T. and Bentler, P. M. (1999). Cutoff criteria for fit indexes in covariance structure analysis: Conventional criteria versus new alternatives. Structural Equation Modeling: A Multidisciplinary Journal, 6(1), 1-55. doi.org/10.1080/10705519909540118

Jabeen, S. and Hamid, A. B. A. (2019). Customers Switching Intentions Behavior in Retail Hypermarket Kingdom of Saudi Arabia: Customers Switching Intentions Behavior in Retail Hypermarket. Partridge Publishing.

Karataş, Z. (2020). COVID-19 pandemisinin toplumsal etkileri, değişim ve güçlenme. Türkiye Sosyal Hizmet Araştırmaları Dergisi, 4(1), 3-15.

Kline, R. B. (2010). Principles and Practice of Structural Equation Modeling. (3rd.ed.). Guilford Press.

Meral, B. (2020). E-ticarette coronavirüs (Covid-19) etkisi. https://www.techinside.com/e-ticarettecorona-virus-covid-19-etkisi/ Erişim Tarihi: 08.06.2020.

Meyer, S. (2020). Understanding the COVID-19 effect on online shopping behavior. https://www.bigcommerce.com/blog/covid-19-ecommerce/\#understanding-panic-buyingand-coronavirus Erişim Tarihi: 05.06.2020. 
Nielsen (2020, February 3) Koronavirüsün global tüketiciler üzerindeki etkileri https://www.nielsen.com/us/en/insights/article/2020/nielsen-investigation-pandemicpantries-pressure-supply-chain-amidst-covid-19-fears/ Erişim Tarihi: 05.06.2020.

Schumacker, R. E. and Lomax, R.G. (1996). A Beginner's Guide to Structural Equation Modeling. Lawrence Erlbaum Associates.

Şimşek, Ö. F. (2007). Yapısal Eşitlik Modellemesine Giriş Temel İlkeler ve Lisrel Uygulamaları. Ekinoks.

Taylor, S. (2019). The psychology of pandemics: Preparing for the next global outbreak of infectious disease. Cambridge Scholars Publishing.

T.C. Sağlık Bakanlığı. (2020). COVID-19 (SARS-CoV-2 Enfeksiyonu) rehberi. https://covid19bilgi.saglik.gov.tr/depo/rehberler/COVID-19_Rehberi.pdf Erişim Tarihi: 02.06.2020.

TRT Haber (2020). https://www.trthaber.com/haber/yasam/koronavirus-onlemleri-evde-ekmekyapimini-artirdi-471950.html Erişim Tarihi: 06.06.2020.

Torun-Kayabaş1, E. (2020). Covid-19'un piyasalara ve tüketici davranışlarına etkisi. Avrasya Sosyal ve Ekonomi Araştırmaları Dergisi, 7(5), 15-25.

Yavuz, F. (2020, Mayı). Tarıma koronavirüs etkisi. Kriter Dergisi, 46, https://kriterdergi.com/ekonomi/tarima-koronavirus-etkisi Erişim Tarihi: 06.06.2020.

World Health Organization [WHO]. (11 Mart 2020)Coronavirus disease 2019 (COVID-19) Situation Report-51. $\quad$ https://www.who.int/docs/default-source/coronaviruse/situationreports/20200311-sitrep-51-covid-19.pdf?sfvrsn=1ba62e57_10 Erişim Tarihi: 08.06.2020.

World Health Organization [WHO]. (2020a). Q\&A on coronaviruses (COVID-19). https://www.who.int/emergencies/diseases/novel-coronavirus-2019 Erişim Tarihi: 03.06 2020. 